\title{
FLAVIN CONTENT IN CAT AND DOG CHOROIDS
}

\author{
Kunio Matsui and Kazunori YanaGIYA*1 \\ Division of Biology, Research Institute for Atomic Energy, Osaka City University \\ * Department of Neuropsychiatry, Osaka City University \\ Graduate School, Sumiyoshi-ku, Osaka, Japan
}

(Received February 2, 1973)

\begin{abstract}
Flavin content in cat, dog choroids and cat tapetum were estimated. The content in cat choroid was nearly as high as that in the cortex of cat kidney and about 11 times of that in dog choroid. The flavin content in cat choroid was related to the presence of melanin, and that in white choroid of cat was very low. The content in cat tapetum was not so high as reported by other investigators. The difference in flavin content between right and left choroids of cat was insignificant. It was also shown that the major flavin in cat and dog choroids is unphosphorylated $\mathrm{RF}^{2}$.
\end{abstract}

Since vON Euler and AdLer (1) found a high level of flavin in the pigment epithelium of retina of some fish, many investigators have studied it in the eyes of various animals. Among them, MANABE (2) estimated flavin in cat and dog choroid retinae, and Elliot and FutTERman (3) in cat tapetum. The authors estimated flavin in cat and dog choroids emphasizing the physiological role of flavin compounds. Fairly different values of flavin content from previous investigators were obtained.

\section{EXPERIMENTAL}

Materials. Eyes and other tissues were obtained from a slaughter, and choroid and tapetum were prepared by HosoyA's method (4). The cat eyes, liver, and kidneys were treated 5-8 hr after death, and dog eyes 2-3 hr after. The white choroids of cat, containing no melanin, were pooled in a freezer at $-20^{\circ} \mathrm{C}$.

RF was obtained from the National Institute of Hygienic Sciences, and FMN from Wako Pure Chemical Industries, Ltd. NF was prepared from cat choroid by Matsui's method (5).

Room lighting. All the procedures were performed in a dark room under a sodium lamp (Toshiba NA-60) to protect the flavin from photodecomposition.

1 松井邦夫, 柳谷和紀

2 Abbreviations used are: RF, riboflavin; FMN, flavin mononucleotide; NF, nekoflavin. 
Estimation of flavin. Flavins were estimated by YAGI's lumiflavin fluorescence method (6). However, preextraction with chloroform and oxidation with permanganate were omitted because the tissues used had no interfering substance. The fluorescence of lumiflavin in chloroform was measured with a Hitachi spectrophotometer EPU-2A and fluorescence attachment T-1L (filter 47). The amount of flavin was calculated assuming that all lumiflavin was formed from RF.

Thin layer chromatography. Merck's Kieselgel G nach Stahl for thin layer chromatography was used. Samples were developed with isoamyl alcohol-methyl ethyl ketone-acetic acid-water (40:40:7:13 by volume) at room temperature for $1.5 \mathrm{hr}$. The spots of flavins were detected by fluorescence under a UV-lamp $(366 \mathrm{~m} \mu)$.

\section{RESULTS}

1. Flavin content in cat and dog choroids, and cat tapetum

For flavin estimation each cat choroid was extracted with $25 \mathrm{ml}$ of water. But as the cat choroid containing no melanin, the cat tapetum, and the dog choroid were poor in flavin, each sample of several pieces was extracted with $10 \mathrm{ml}$ of water. The flavin contents in the eye tissues were compared with those in liver and kidney. The results are shown in Table 1.

Table 1. Flavin content in dog and cat choroid, cat tapetum, liver and kidney.

\begin{tabular}{lccccc}
\hline \multicolumn{2}{c}{ Material } & \multicolumn{5}{c}{ Average flavin content $(\mathrm{M} \pm \mathrm{SD})$} \\
\hline \multicolumn{1}{c}{ Melanin } & Tapetum & $\mu \mathrm{g} / \mathrm{g}$ fresh tissue & $\mu \mathrm{g} / \mathrm{g}$ dry tissue & $\mu \mathrm{g}$ each piece \\
Dog choroid & + & + & $6.51 \pm 2.41^{\mathrm{a}}$ & $29.73 \pm 11.00^{\mathrm{b}}$ & $0.42^{\mathrm{a}}$ \\
Cat choroid & + & + & $70.95 \pm 34.21^{\mathrm{c}}$ & $337.9 \pm 162.9^{\mathrm{d}}$ & $3.98^{\mathrm{c}}$ \\
& - & + & & $19.0^{\mathrm{e}}$ & $0.17^{\mathrm{f}}$ \\
& - & - & & $10.6^{\mathrm{g}}$ & $0.031^{\mathrm{f}}$ \\
Cat tapetum & & & & $43.52 \pm 18.31^{\mathrm{h}}$ & $0.118^{\mathrm{h}}$ \\
Cat liver & & & $25.7 \pm 3.82^{\mathrm{i}}$ & & \\
Cat kidney & & & & \\
$\quad$ Cortex \\
Medulla
\end{tabular}

a Obtained from 14 samples of 4 choroids.

b Calculated from water content $78.1 \%$ of dog choroid (7).

c Obtained from 144 cat choroids.

d Calculated from water content $79.0 \%$ of cat choroid (7).

e Obtained from 7 samples weighing $20-40 \mathrm{mg}$.

$f$ Obtained from a sample of 12 choroids.

g Obtained from 7 samples weighing $25-60 \mathrm{mg}$.

$\mathrm{h}$ Obtained from 10 samples of paired tapeta.

i Obtained from 20 livers.

j Obtained from 19 kidneys. 
The flavin content in the choroids of some animals is very high, the highest value being that of frog, $2186 \mu \mathrm{g} / \mathrm{g}$ of fresh tissue which was reported by YAGI (8). Next is that of pigeon, reported by MANABE (2), $124 \mu \mathrm{g} / \mathrm{g}$ of fresh tissue, which is the content in choroid combined with retina. Though the flavin content in cat choroid is lower than those described above, it is higher than those in other animals such as cattle (2), and is comparable to that in cortex of kidney.

The flavin content in cat choroid containing melanin is very high; it is about 11 times of that of dog choroid, and higher than that of cat liver and comparable with that of cortex of cat kidney. The flavin content in white choroid of cat, especially that in choroid containing neither melanin nor tapetum, is very low. Therefore, cat choroids are classified in two groups, one is the white choroid group containing no melanin and very little flavin and the other is the black choroid group containing melanin and abundant flavin.

Table 2. Flavin content of paired right and left cat choroids.

Snedecor's $F$-test: $\quad F=1.043<F_{24}^{24}(0.05)=1.98$.

Student's $t$-test: $\quad t=0.205<t_{48}(0.05)=2.01$.

\begin{tabular}{ccc}
\hline Choroid & No. of sample & $\begin{array}{c}\text { Flavin content } \\
(\mathrm{M} \pm \mathrm{SD})\end{array}$ \\
\hline & & $\mu \mathrm{g} / \mathrm{g}$ fresh tissue \\
Right & 25 & $76.8 \pm 34.16$ \\
Left & 25 & $78.8 \pm 33.45$ \\
\hline
\end{tabular}

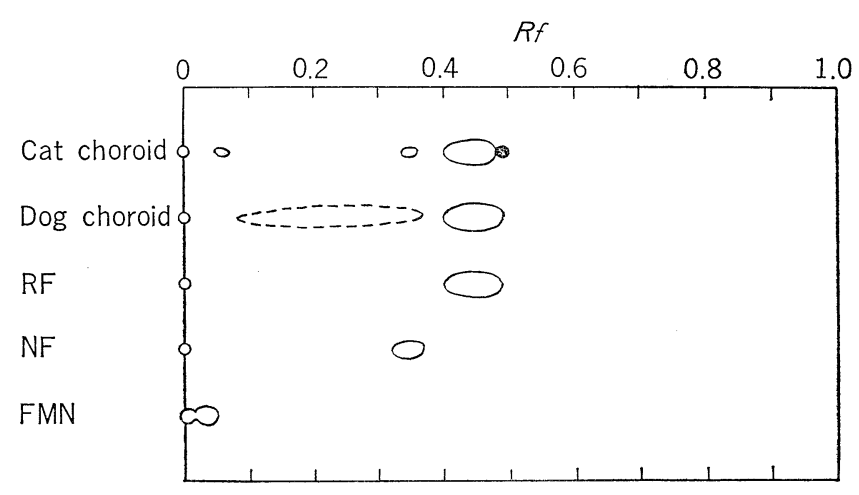

Fluorescence, Ogreenish-yellow; $\because$ bluish-white; blue.

Fig. 1. Thin layer chromatogram of extracts of cat and dog choroids. The extract $(100 \mathrm{ml})$ from 5 pieces of cat choroid was concentrated, and spotted. The extract $(700 \mathrm{ml})$ from $100 \mathrm{~g}$ of dog choroid was deproteinated with trichloracetic acid, and passed through a Florisil column $(2 \times 7 \mathrm{~cm})$, which was washed with water and $0.5 \%$ aqueous pyridine. The $5 \%$ pyridine eluate was concentrated after washing with chloroform to remove pyridine, and spotted. 
The flavin contents in right and left choroids were compared using paired eyes (Table 2). Snedecor's $F$-test and Student's $t$-test $(9)$ show that no significant difference was found between flavin contents in choroids of both sides. Therefore, one side of paired choroids can be used as a control for the other side in experiments.

\section{Thin layer chromatography of flavins in cat and dog choroids}

The thin layer chromatogram of extracts of cat and dog choroids is shown in Fig. 1. The RF values of the major flavin found in the extracts of cat and dog choroids coincided with that of RF. One of two small spots in the extract of cat choroid corresponded to that of NF.

It is well known that flavin in choroids $(8,10)$ and pigment epithelium of retina (11) is unphosphorylated. Figure 1 shows that in the extracts of cat and dog choroids the major flavin is unphosphorylated RF. NF, one of the minor flavins found in cat choroid (Fig. 1), is supposed to be unphosphorylated (12). Therefore, almost all of the flavins in cat and dog choroids are unphosphorylated, though another minor flavin in cat choroid was not identified.

\section{DISCUSSION}

The flavin contents in cat and dog choroids (combined with retinae) were measured by MANABE (2) who reported that the former was 0.33 and the latter $0.44 \mu \mathrm{g}$ for each piece of tissue. Our corresponding values are 3.98 and $0.42 \mu \mathrm{g}$ for each piece of tissue. MANABE's value for dog coincides with ours, but that for cat is only $1 / 12$ of ours. We suppose that in his procedure the extraction of flavin from cat choroid might be incomplete.

The flavin content in cat choroid is related to the color of the choroid. Table 1 shows that the content in white choroid having neither melanin nor tapetum is only about $1 / 32$ of the content in black choroid having melanin, and that flavin has some intimate relation to melanin. Similar relation between melanin and flavin was reported by Aso et al. (13) who showed that human and animal hair and skin having more melanin contained more RF. In another report (14) we have shown that flavin is associated with melanin in the black choroids of cat and dog.

The flavin content in cat tapetum was reported by ELLIOT and FUTTERMAN (3), whose value of dry tissue, $70-250 \mu \mathrm{g} / \mathrm{g}$, is apparently much higher than ours, $43.52 \pm 18.31$, and is between our values of cat tapetum and of choroid. We wonder if their tapetum preparation might be contaminated with choroid as they didn't describe how to isolate tapetum. Another report of flavin in tapetum is that by PIRIE (15), who showed that the tapetum of lemur choroid contains crystals of RF. We have no evidence that the flavin in cat tapetum is in the form of crystals, but from evidence described in another report (14), we suppose that the flavin is in associated form with rodlets. 
Authors thank Prof. K. Uehara of Osaka University for discussing this work, and Assistant Prof. Kitabatake of Osaka City University for his advice on statistics.

\section{REFERENCES}

1) von Euler, H. and Adler, E., Z. physiol. Chem., 223, 105 (1934).

2) Manabe, M., Nippon Gankagakkai Zasshi (in Japanese), 44, 1171 (1940).

3) Elliot, J. H. and Futterman, S., Arch. Ophthalmol., 70, 531 (1963).

4) Hosoya, Y., Tohoku J. Exptl. Med., 12, 119 (1929).

5) Matsui, K., in D. B. McCormick and L. D. Wright (Editors), Methods in Enzymology, Academic Press, New York, Vol. XVIII B, p. 433 (1971).

6) YAGI, K., in D. Glick (Editor), Methods of Biochemical Analysis, Interscience Publishers, New York, Vol. X, p. 319 (1962).

7) YanagiYa, K. and Matsui, K., Osaka Shiritsudaigaku Igaku Zasshi (in Japanese), 20, 329 (1971).

8) Yagi, K., Jap. J. Physiol., 2, 27 (1951).

9) Fisher, R. A., Statistical Method for Research Workers, Oliver and Boyd, Edinburgh (1950).

10) Brunner, O. and BARONI, E., Sitzungsberichte der Kaiserliche Akademie der Wissenschaften in Wien, Mathematische-naturwissenschaftliche Klasse, Abt. II b, 145, 484 (1936).

11) VON Euler, H. and Adler, E., Nature, 141, 790 (1938).

12) MASUOKA, M., Vitamins, 47, 13 (1973).

13) Aso, K., Utsumi, K., Tsuchiya, H., and Takeuchi, K., Nippon Hifukagakkai Zasshi (in Japanese), 71, 475 (1961).

14) Matsui, K. and YanagiYa, K., J. Nutr. Sci. Vitaminol., 19, 193 (1973).

15) PIrIE, A., Nature, 183, 985 (1959). 